UNIVERSIDADE DE SAO PAUIO

ESCOLA POLITKCNICA -- LABORATORIO DE BIOQUIMICA

Diretor: Prof. Dr. Renato Fonseca Ribeiro

FACLLDNJI: DE MHDICINA VUPERINARIA

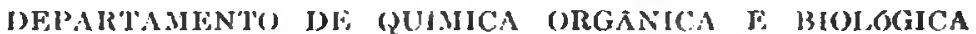

Diretor: Prof. Dr. lionseca Riluciro

\title{
DETERMINAÇÃO DO CÁLCIO, FôSFORO, FERRO E CINZAS EM ALGUMAS HORTALIÇAS DA FAMİLIA DAS CRUCIFERAE
}

COUVF, VERDE (Brassica oleracea, I. var. acephala, D.C.) e COUVE TRONCHUDA (Brassica oleracea, L. var. bullata, D.C.) ; REP(OLHO Brassica oleracea, I. var. capitata, L.); AGRIñO D'ACUA (Roripa nasturtium, Rusby)

CALCICM, PHOSPHORUS, IRON AND ASHES DETERMINATION IN SOME VEGETABLES IN TIL FAM. CRUCIFERAE

Roberto Roperto

Virgílio Bonoldi

Isaltina Prestes Monzoni

As hortaliças representam, na alimentaçāo do homem, um complemento ali. mentar dos mais estimáveis, visto que, além de outras caracteristicas importantes, fornecem ao organismo substâncias minerais necessárias à manutenção do equilíbrio funcional. A determinação do conteúdo mineral das diversas hortaliças utilizadas na alimentaçāo já despertou a atenção de vários pesquisadores, sobretudo alienígenas, e não cabem aqui as considerações atinentes à composição dos alimentos cujo desenvolvimento esteve sujeito às condiçōes ecológicas diversas das nossas. Em vista disso, propusêmo-nos determinar os elementos minerais que julgamos de mais ressaltante importância, em legumes de maior consumo em nosso meio. Assim sendo, nossa atenção concentrou-se na determinação do fósforo, cálcio e ferro, além do conjunto mineral total representado pelas cinzas. 0 presente trabalho é, pois, apresentação de dados obtidos a propósito dêsses elementos em algumas hortaliças da família das Cruciferae, e a êle se 
seguirāo, em próximas publicaçōes, outros referentes às famílias das Composilae, Chenopodiaceae, Umbelliferae, Cucurbilaceae, etc..

\section{WATYKLA, F, MUYONOS}

Das hortaliças cujos dados mais adiante estão tabelados: cuidamos que a: amostras apresentassem a parte pròpriamente comestivel, além de, tambim, a:segurarmo-nos de que houvessem sido produzidas nas chácaras dos arredores da Capital ou dos centros produtores que a abastecem habitualmente. Estes cuidados permitem apresentar aos nutrólogos valôres para a formulação de raçóes alimentares.

Os métodos aplicados na determinação foram os clássicos e a seguir us transcreveremos para esclarecimento dos interessados.

Determinação das cinzas -.- Lavar o vegetal em água corrente, a fim de afastar todo o detrito de terra ou outra impureza aderentc. A seguir, enxugar com papel de filtro ou pano, empregando hranda compressāo. Do materiat assim tratado, tomar $100 \mathrm{~g}$, carhonizar e calcinar entre $600.650^{\circ} \mathrm{C}$. Após res. friamento, determinar a massa das cinzas. Seja $l$ o valor achado:

1) - $\mathrm{CH} 6 \mathrm{~N}$

8) $-\mathrm{Cl}_{9} \mathrm{Sn} .2 \mathrm{I}_{2} \mathrm{O}-25 \mathrm{gem} 10 \mathrm{ml} \mathrm{de}$ Cll. Diluir :2 $100 \mathrm{ml}$.

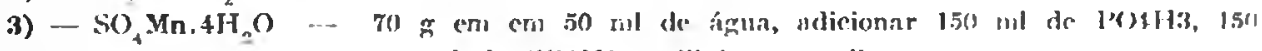
mI de SOHIle a diluir : um litro.

4) $-\mathrm{Cl}_{2} \mathrm{Hg}_{\mathrm{g}} \quad-80 \mathrm{~g} / \mathrm{l}$.

5) - MnO4k 0,1 $\mathrm{N}$ - Suluçãn imutrion.

Tomar cêrca dé $90 \%$ da cinza obtida e tratar com $20 \mathrm{ml}$ de ácido clori. drico $6 \mathrm{~N}$. Deixar ferver, filtrar se houver necessidade. Vo filtrado, a quente. adicionar, à gôtas. a soluçäo de clorêto de estanho 11. em quantidade apenas suficiente para reduzir o ferro ao estado ferroso; resfriar, diluir, adicionar $5 \mathrm{~m}$ ! da solução saturada de clorêto de mercúrio II. Diluir a $100 \mathrm{ml}$, adicionar $20 \mathrm{ml}$ da solução de sulfato de manganês II e titular com solução $0,1 \mathrm{~N}$ de $\operatorname{Mn}(\mathbf{M} K$.

Cálculo ... Sendo P o valôr em gramas da massa total do resíduo da cal. cinação (cinzas): designando-se por $P_{1}$ o correspondente ao material retirado) da cinza (cêrca de $90 \%$ do total); e por a o número de ml da solução de permanganato consumido; a porcentagem de ferro no vegetal fresco $\dot{e}$ dada pela relação:

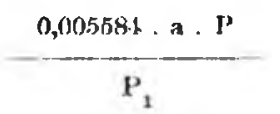


Tratar o malerial restante da cinza inicial com $10 \mathrm{ml}$ de NO3H $6 \mathrm{~N}$. Deixar ferver por 3 a 5 minutos e filtrar se houver necessidade. Diluir a solução a $100 \mathrm{ml}$ num halão aferido.

\begin{tabular}{|c|c|c|c|c|}
\hline & Delermimeseres ab eriltion & & stolucion: & Iererssuriri \\
\hline 1) & (OHNH $6 \mathrm{~N}$ & & & \\
\hline 2) & (Dailato de: immonio & - & Suluc̣āu & sulurata. \\
\hline :\$) & $S(0.1122 \mathrm{~N}$ & & & \\
\hline 4) & Vermelho de metili & - & Soluc̆ũen & $10 \mathrm{~g} / \mathrm{I}$ \\
\hline 5) & NOBII i $\mathrm{N}$ & & & \\
\hline (i) & $\mathrm{MnO}, \mathrm{K} 0,1 \mathrm{~N}$ & - & Soluçio & pacirãu. \\
\hline
\end{tabular}

Tomar alíquota de $50 \mathrm{ml}$ da solução, adicionar $100 \mathrm{ml}$ de água, 2 a 3 gôlas da solução de vermelho de metila e, em seguida, OHNH46 N, cuidadosamente, até mudança de côr. Adicionar NO3H $6 \mathrm{~N}$ o suficiente para que a solução fique alaranjada. Levar à ebulição e adicionar $5 \mathrm{ml}$ da solução sa. lurada de oxalato de amônio.

Ferver até aglomerar o precipjitado. Filtrar e lavar com água quente até -liminar o excesso de oxalato. Desprezar o filtrado. Dissolver o oxalato de (álcio em $100 \mathrm{ml}$ de $\mathrm{S} 04 \mathrm{H} 22 \mathrm{~N}$. aquecex a $60-70^{\circ} \mathrm{C}$ c titular com solução de $\mathrm{UnO} 4 \mathrm{~K} 0,1 \mathrm{~N}$.

Cálcule - Designando-se por l', o valor em gramas da massa restarite; por $a$, os $\mathrm{ml}$ do permanganato gastos: a porcentagem do cálcio no vegetal é lada pela expressão:

$$
\frac{\left(1,0020 \cdot a_{1} \cdot r^{\prime}\right.}{P_{2}}
$$

Determinarenes do fosfuro

: voluçöes necesscirine

1) - Vermelho de: metila $10 \mathrm{~g} / \mathrm{l}$

2) - OHNH46 N

i) -.. NO8H i $\mathrm{N}$

1) - Soluçǟo nitro-molibdato de amoniov:

85 is de (08Ho em $240 \mathrm{ml}$ de águs. Adicionar $1.0 \mathrm{ml}$ OHNIIt e $60 \mathrm{ml}$ de NO3H. Deixar esfriar. Adicionar $1.400 \mathrm{ml} k$ $\mathrm{NO} H+\mathrm{N}$.

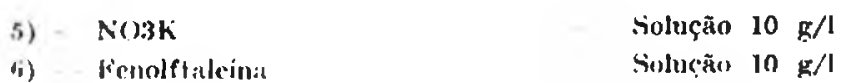

Tomar os $511 \mathrm{ml}$ restantes da solução. adicionar 2 as :i gôlas da solução de vermelho de metila e adicionar OHNHA até reação ligeiramente alcalina. Adicionar $2 \mathrm{ml}$ de $\mathrm{NO} 3 \mathrm{H} 6 \mathrm{~N}$ e. em seguida, $100 \mathrm{ml}$ de água. Ferver por 2 a $3 \mathrm{mi}$ untos. deixar esfriar dr modo a manter a temperatura entre $60.70^{\circ} \mathrm{C}$ e adicio- 
nar $20 \mathrm{ml}$ da solução nitro-molibdato de amônio. Agitar vivamente até for. mar-se o precipitado. Manter a $60^{\circ} \mathrm{C}$ até depositar-se o precipitado. Filtrar em cadinho de Gooch preparado com polpa de papel de filtro. Lavar duas vezes com NO3H 0,3 N e, em seguida. com solução de $\mathrm{NO}) 3 \mathrm{~K}$ até cessar a rea(ūo ácida do líquido de lavagem.

Passar cuidadosamente a polpa para o frasco em que se procedeu à preci. pitação. Iransferindo quantitativamente o precipitado amarelo. Adicionar 100 ml de água e desfazer a polpa. Adicionar quantidade medida da solução de OHNa $0,1 \mathrm{~N}$ até dissolver o precipitado. Adicionar 2 a 3 gôtas da solução de fenolftaleína e litular a frio o excesso de álcali con a soluçāo pradräo de NO3H $0.1 \mathrm{~N}$.

Cálculo - Designando-se por $a_{t}$ e $a_{s}$, respectivamente, os volumes consumidos de hidróxido de sódio e ácido nítrico $0.1 \mathrm{~N}$. a porcentagem de fósforo no vegetal é dada pela expressāo:

$$
\frac{\left(a_{2}-a_{3}\right) 0,000135 . p}{P_{n}}
$$

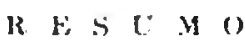

Os autores determinaram pelos métodos correntes clássicos os teôres de cál. cio, fósforo e ferro, além das cinzas, em diversas hortaliças da família das Ciruciferae, ou seja, na couve verde (Brassica oleracea. I. var. acephala. D.C.); couve: tronchuda (Brassica oleracea. I. var. bullata. D.C.); repôlho (Brassica oleracea, L. var. capitata, L.) ; agriāo d’àgua (Koripa nasturlium, Rusby). Encontraram como media os resultados das determinaçōes realizadas sôbre dezes. seis amostras de cadi uma das citadas hortaliças. e em estado crú. os seg̣uintes valores ( $\mathrm{mg}$ para $100 \mathrm{~g}$ de amostra) :

\begin{tabular}{|c|c|c|c|c|}
\hline & rin:ass & Fe & $r a$ & $r$ \\
\hline Couve tronchuda & 1565 & 5,1 & 210,4 & $\cdot, 4,3$ \\
\hline$\ldots \ldots \ldots \ldots$ & 1551 & 3,0 & 260,0 & 14,5 \\
\hline Repollon $\ldots$. & $x \geq 1$ & 3,4 & $\pi \pi, 0$ & $\$(0,2$ \\
\hline Agrião d’águн & 1109 & 3,8 & 105,9 & 13,3 \\
\hline
\end{tabular}

A relação cálcio-fósforo é: para a couve tronchuda … 4,3:1: para a couve verde - 6:1; para o repôlho - 2:1; e para o agriāo d’água - 2.5:1.

Tais dadus referem-se à parte comestivel do vegetal e de exemplares pro. venientes das chúcaras dos arredores de São Paulo ou dos outros produtores que o abastecem normalmente. 


\begin{tabular}{|c|c|c|c|c|c|c|c|c|c|c|c|c|c|c|c|c|}
\hline & \multicolumn{4}{|c|}{ CINZst (ng/100 g) } & \multicolumn{4}{|c|}{ FERRO $(m g / 1(k) k)$} & \multicolumn{4}{|c|}{ CALCIO (mg/100 g) } & \multicolumn{4}{|c|}{ FOSFORO (nug/100 g) } \\
\hline & 竞 & 竎 & 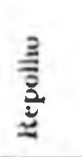 & 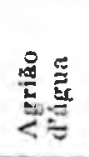 & 趇 & 常 & 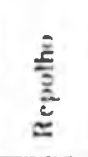 & 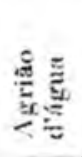 & 竎 & 总苛 & $\frac{\frac{5}{3}}{\frac{2}{x}}$ & 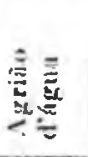 & 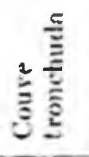 & 产 & 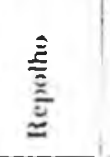 & 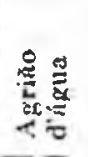 \\
\hline I & 1519 & 1788 & 1066 & 93.4 & 3,0 & 1,5 & 1,6 & 3,0 & 198,6 & 336,6 & 35,8 & 79,8 & 50,8 & 40,9 & 17,8 & 42,9 \\
\hline$\because$ & 1447 & 15.8 & 953 & 907 & 3,0 & 0,8 & 2,1 & 2,5 & 211,7 & 384,8 & 22,3 & 64,3 & 35,6 & 54,3 & 16.2 & 48,9 \\
\hline 3 & $133: 2$ & 1300 & 918 & 872 & 3,0 & $4, \pi$ & 2.4 & 3,1 & $21:, 9$ & $3(60,0)$ & 83,6 & $5 \cdot+, 1$ & 38,0 & 21,4 & 59,2 & 39,6 \\
\hline$t$ & $11+46$ & 2224 & 631 & 90 & $16, \$$ & 5,7 & 1,8 & 2,4 & 255,3 & 568,0 & 40,0 & 106,2 & 44,4 & 38,9 & 50,3 & 15,5 \\
\hline 5 & $127 \tau$ & 1189 & 761 & 899 & $t, 1$ & 2,5 & 2,4 & $\geq 9$ & $231, \pi$ & 405,6 & 10, 0 & 85,1 & $41, \underline{2}$ & 94,2 & 54,4 & $4.5,8$ \\
\hline ii & $1+51$ & 1450 & 673 & 902 & 3,0 & 1,9 & 1,3 & 4,0 & $2.43,5$ & 302,5 & 57,2 & 121,7 & 34,0 & 46,9 & $10, \pi$ & 72,1 \\
\hline$i$ & $1+\pi 1$ & 1409 & 802 & 99.1 & $(i, 4$ & 1,9 & 1,5 & +6 & $2+18, \pi$ & 254,3 & 61,7 & 93,3 & 50,0 & $\$ 6,1$ & 29,8 & 63,5 \\
\hline 8 & 1503 & $1+22$ & 6773 & 904 & 5,3 & 2,2 & 1,3 &,+ 0 & 245,1 & 610,4 & 51,8 & 97,0 & 69.3 & 108,0 & 40,6 & $\$ 1,9$ \\
\hline 9 & 1684 & 1702 & 557 & 1038 & 8,0 & 3,6 & 1,2 & 4,1 & 102,9 & 103,10 & 39,3 & 103,0 & 49,5 & 39,8 & H, & 18,6 \\
\hline In & 1651 & 1783 & 616 & 1223 & $4, \pi$ & 2,9 & 1,2 & 3,0 & 271,4 & 246,9 & 48,7 & 51,3 & 48,5 & $4+, 0$ & 67,8 & 15,1 \\
\hline Il & 1618 & $1 \pi 38$ & 693 & 1182 & , i, & 1,1 & 1,8 & $2, k$ & $9 \cdot,, i$ & 95,2 & 43,8 & 118,5 & 61,5 & 64,3 & 35,0 & 29,4 \\
\hline 12 & 2162 & 1190 & 671 & 1372 & 7,2 & 3,0 & 1,5 & 2,9 & $28: 3,9$ & 62,3 & 36,4 & 121 & $6 \pi, 5$ & 22,7 & 35,9 & 28,3 \\
\hline 13 & $17 \% 2$ & $1 .+20$ & 18.49 & 1362 & 4,0 & 5,4 & 3,5 & 5,9 & 215,2 & 66,4 & 178,7 & 185,0 & 45,8 & 25,5 & 58,8 & 46,0 \\
\hline 11 & $161 \%$ & 1507 & 1556 & 1537 & 3,5 & 5,8 & $4, ?$ & 5,2 & 171,4 & 75,7 & 188,1 & 171 & $\$ 1,+$ & 28,9 & 50,6 & 42,3 \\
\hline 15 & 1690 & $12+8$ & 1803 & 1931 & 2,9 & 3,6 & 5,5 & 5,8 & 102.7 & 60,8 & 266,7 & 129,9 & $4+, 3$ & 9,9 & 24,1 & 42,6 \\
\hline$l i \mathrm{i}$ & 1502 & 1597 & 628 & 1462 & 4,7 & 1.7 & 21,9 & 5,3 & 184,1 & 224.0 & 12,2 & 115,8 & 48,6 & 25,9 & 21,3 & 39,3 \\
\hline M & 156.5 & 1551 & 921 & 1109 & 5,1 & 3,0 & 3,1 & 3,8 & 210,4 & $26 i n, 0$ & $i \check{s}, 0$ & 105,9 & 48,3 & 44,5 & 40,2 & 43,5 \\
\hline$\sigma$ & 202 & $2+i$ & 417 & 231 & 3,3 & 1.5 & 4,9 & 1,1 & $51 . \mathrm{K}$ & 172,6 & 69,2 & 35,9 & 9,8 & 28,1 & 15,2 & 12,7 \\
\hline$v$ & 12,9 & 15,9 & 45,8 & 20,9 & 64,7 & 50,0 & 14,4 & $\mathbf{2 8 , 9}$ & 24,6 & 66,3 & 92,2 & 33,8 & 20,2 & 63,1 & 37,8 & 29,1 \\
\hline
\end{tabular}

